\title{
Wide variations in child dental
}

\section{health found}

A report into the state of pre-school children's dental health across the South East has found wide variations in dental health in the region. Published by the South East Public Health Observatory (SEPHO), the report looked at dental health in five-yearolds by analysing data from Primary Care Trusts (PCTs) and Strategic Health Authorities (SHAs) across the South East between 1995 and 2002. It found that dental health in young children had improved across the South East since 1995, and was above the national average but that there were wide variations between different areas, with some groups of children suffering significant levels of damaged teeth.

Kent and Medway SHA had the best record on dental health and met the 2003 national target for oral health in five-year-olds. The SHA had the lowest average number of decayed, missing or filled teeth in 2001-2002 while the areas of Thames Valley had the worst.

The report continues to say that although fluoridation of water and other dental products is a proven method of preventing tooth decay, no areas of the South East have fluoridated water supplies. The report also found a link between wealth and dental health with the less affluent areas of the region having a worse record on dental health. Further work is taking place to investigate other reasons behind the inequalities highlighted by the report.

Alison Hill, Director of SEPHO said: "This is the biggest study into the state of young children's teeth in the South East in recent years and it provides some valuable information for dentists and parents. Although the region as a whole compares well with others, we are concerned by the poor record on dental health in some parts of the region and by the reversal in improvements across the region in the last three years of the study."

The study recommended that PCTs should develop dental health strategies, identifying inequalities and develop targeted, preventive services. SEPHO is now working with public health dentists to urge the NHS and Local Authorities to address the issues raised by the report; this includes considering the fluoridation of public water supplies and the implementation of other prevention strategies in the areas with high levels of tooth decay. The report is available online at www.sepho.org.uk or by calling 01865334714.

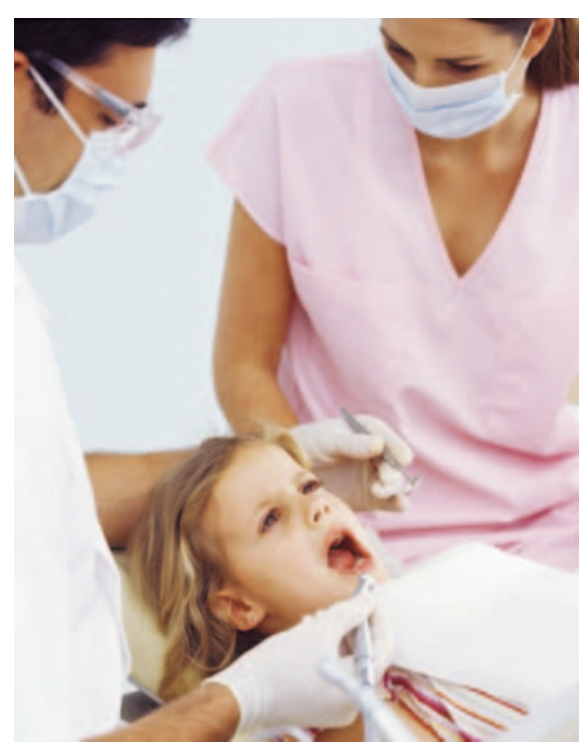

\section{New measures for GDC announced}

New powers for the General Dental Council (GDC) to protect patients have been announced by Health Minister Rosie Winterton. These include measures to tackle problems highlighted in a report on the private dentistry market in the UK by the Office of Fair Trading (OFT). Patients complained that they were not given adequate information to make informed choices about their treatment and often do not know how much their treatment is going to cost.

The Order, made under Section 60 of the Health Act, will allow the GDC to establish a complaints scheme for non-NHS patients to complain about their dental care. For example, dentists are expected to agree a patient's treatment costs in advance. If the patient then finds that, without their consent, the costs substantially exceed this

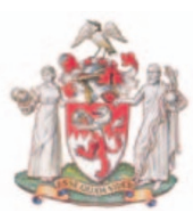

\section{General Dental Council}

agreed amount, the new measures give the patient the means to complain.

This Order will also empower the GDC to address the other concerns highlighted in the OFT report by: introducing compulsory indemnity cover for dentists before registration, so that dentists who are found to have harmed patients are insured and able to pay compensation; safeguarding patients by giving the GDC the power to extend regulation to other professionals working within dentistry, including dental technicians and nurses; and modernising the Council's 'fitness to practise' procedures for dealing with misconduct and ill health amongst dental professionals, and introduce new procedures to tackle problems of poor performance.

Rosie Winterton said, "These measures will make sure patients get a fair deal and clear information when they receive dental treatment. Through these new powers, the General Dental Council is better placed to assure the quality of care that patients receive and provides a more robust and effective complaints system to take early action when things go wrong." She added that ensuring dentists had proper indemnity cover before they registered was an important extra protection for patients and could avoid cases in which patients have sued for damages and then found the dentist could not pay. 